\title{
THE
} JUBILEE CENTRE FOR CHARACTER \& VIRTUES

\section{Insight Series}

Moving Towards Virtuous Professional Practice: A Summary of a Content Analysis of Professional Regulatory Documents and Codes of Conduct

\author{
Dr Stephen Earl
}

Jubilee Centre for Character and Virtues

Dr Maria Moulin- Stożek

Jubilee Centre for Character and Virtues 


\section{Moving Towards Virtuous Professional Practice: A Summary of \\ a Content Analysis of Professional Regulatory Documents and \\ Codes of Conduct}

\section{INTRODUCTION}

The growing focus on professional ethics within the fields of moral philosophy (Moore, 2017) and positive psychology (Peterson et al., 2010) is testament to the valuable ethical role that the professions are perceived to play in modern society. These expanding volumes of literature give emphasis to a normative conception of professionalism and 'good' service that is grounded in moral principles (Carr, 2018). Practitioners in professional roles are expected to conduct ethical practice in the best interest of the individuals they serve, the organisation they operate within, and wider society at large (Jubilee Centre, 2016). Although such ethical practice has long been expected from occupations traditionally deemed to be 'professions' (e.g. medicine and law), moral professionalism has now become widely demanded from the majority of human occupations (e.g. teaching, social work, nursing, business, and emergency services). Good professional practice extends beyond a mastery of technical skill or knowledge, and requires practitioners to have a disposition to make critically informed autonomous judgements through a process of moral reasoning (Carr, 2018). Consequently, there is a growing desire to identify and promote the moral implications of professional practice within the guiding regulatory documents, codes of conduct and mission statements that professional bodies and government produce.

The rising incentives for commercial prowess, reputation status and performance statistics may, however, put professional organisations at risk of not capturing the moral dimensions of professional practice within their regulatory guidelines. This is particularly relevant in regards to the qualities of 'good' character and the language of virtue (Carr, 2018; Moore, 2015). The Jubilee Centre for Character and Virtues has conducted a substantial amount of research to explore the development of excellences of character within various UK-based professions in their move towards a greater public good (Arthur et al., 2014; 2015a; 2015b; 2018; Kristjánsson et al., 2017a; 2017b). Founded upon a neo-Aristotelian account of virtue ethics, the Jubilee Centre provides a framework to illustrate how virtuous practice, both in personal and professional life, develops through the habituation of distinct intellectual, moral, performance and civic virtues (Arthur, 2017; Jubilee Centre, 2017). 
Indeed, practitioners' endorsement of such virtues has been associated with greater job performance and satisfaction at work (Harzer and Ruch, 2013; 2014; 2015). These virtues are fundamental to the development of the Aristotelian notion of phronesis, or practical wisdom, through which professionals will learn to practice with deliberation, reflection and professional judgement - even within highly dilemmatic situations - based upon wellchosen moral habits (Carr et al., 2011; Kristjánsson, 2015). Recent findings have revealed that professionals displaying a character profile synonymous with phronetic virtue - that is a collective value of moral, performance and intellectual virtue - were found to report greater senses of professional purpose that extend beyond their professional domain (Arthur et al., 2019).

This evidence notwithstanding, an emphasis towards virtuous qualities seems to be diminishing within professional spheres. Trainee primary and secondary school teachers were found to place increasing importance upon intellectual (e.g. critical thinking) and performance (e.g. perseverance) virtues over the course of their teacher training, whereas the importance they placed upon moral virtues decreased over the same period (Arthur et $a l .$, 2018). Furthermore, practitioners from a range of professions were predominantly found to base their decision-making in professional situations upon rules and regulations as opposed to virtuous deliberations (Arthur et al., 2014; 2015a; 2015b; Kristjánsson et al., $2017 \mathrm{a} ; 2017 \mathrm{~b})$. These greater levels of rule-based reasoning were particularly prominent within pre- and in-service nursing (Kristjánsson et al., 2017b). Business and legal professionals also displayed a tendency to base their professional decision-making on consequentialist reasons, with business professionals often driven by financial motives (Arthur et al., 2014; Kristjánsson et al., 2017a). Investigating how ethical implications for professional practice are expressed explicitly or implicitly within regulatory documents may offer insights into this apparent diminishing emphasis towards morally driven normative working practices.

Based on the aforementioned considerations, this paper outlines a summary of the findings of a content analysis from a collection of UK-based professional mission statements, codes of conduct, and regulatory documents within the professions of medicine, law, teaching, business and nursing. This analysis aimed to identify general similarities and more distinct nuances across professions in the extent they reflected ethical dimensions of their members' practice. Specifically, the content of each document was assessed in regard to who they were written by, who they were targeted towards, the extent they used the language of character and virtue, the degree they promoted independent 
professional judgement, and the degree to which they could be applied by practitioners to their everyday practice. All examined documents are presented in an online appendix (available at: $\quad$ http://www.jubileecentre.ac.uk/userfiles/jubileecentre/pdf/insightseries/VirtuousProfessionalPractice_AppendicesTable.pdf) with the emerging key themes from the analyses outlined and discussed in the subsequent sections.

\section{THE NATURE OF PROFESSIONAL DOCUMENTS}

From an ideal perspective, professional codes should be directed towards fostering a 'moral community' between the professions and the wider society they serve (Sama \& Shoaf, 2008). However, codes of conduct often vary in the degree to which they promote examples of 'good' ethical practice, and have seemingly become aimed primarily at preventing occasions of malpractice and protecting the public from unethical conduct (Furlong et al., 2017; Jamal and Bowie, 1995). The examined documents were predominantly found to be regulatory in nature, portraying a mandatory undertone by which members of a particular profession are required to follow specified rules and normative standards that are enforced by sanctions if not adhered to. The documents rarely refer to ethics, instead using phrases such as standards in medicine, nursing and education, or the term conduct more commonly mentioned in law and business. Other phrases such as duties, rules, obligations and competencies are also used frequently throughout the documents. Such phrasing may be somewhat telling of the high degree of rule-based, rather than virtuebased, reasoning reported by professionals when responding to professional situations (e.g. Arthur et al., 2014; 2015a; 2015b; Kristjánsson et al., 2017a; 2017b). Although some documents do offer guidelines which could be deemed more aspirational (i.e. encouraging professionals to act as role models) or educational (i.e. guiding professionals in enacting their profession's expectations), these examples were scarce and often distinct to a specific sector within a profession. Consequently, there may be a potential risk for these documents to be used retrospectively as a reference or 'checklist' to evaluate if professionals have or have not fulfilled the specified criteria in their conduct, as opposed to guiding professionals in how to conduct future ethical practice.

The documents are issued by a range of stakeholders which vary across professions, including the national government and regulatory professional bodies. Professional documents within UK education are principally specified by the national government, Department of Education (see Appendix Documents 2.1., 2.2. and 2.3), and regard normative teaching standards and responsibilities. These documents provide a framework for schools, teachers and head-teachers to follow in their teaching practice, with 
supplementary documents issued by unions and education societies. Likewise, the Department of Health has issued documents that offer guidance for medical professionals, yet the primary codes of conduct for doctors and nursing are issued by the General Medical Council (see Appendix Document 5.1) and Nursing and Midwifery Council (see Appendix Document 1.1), respectively. Documents concerning the legal and business professions are seemingly issued more at a sector level by regulatory and professional bodies to cover the diverse divisions of law (e.g. see Appendix Documents 3.1, 3.5. and 3.7) and business (e.g. see Appendix Documents 4.1, 4.2., 4.10. and 4.12). Regardless of the source, documents across all professions are still regulatory in nature and attempt to stipulate the expected standards of practice that members must obey.

\section{DISPLAY OF ETHICS}

Across all professions, members are expected and required to display a range of virtues, however the specific virtues are often interpreted differently within given professions. For instance, the virtue of honesty was salient within documents across every profession and has been ranked as the most important virtue by professionals in both their personal and professional domains (see Arthur et al., 2019). Nevertheless, the conceptualisation of honesty was found to differ between professions depending on what the honesty was concerned with in everyday practice. Within business, codes typically referred to honesty in regards to not manipulating information, not influencing the judgement or decision-making of an individual or organisation. In contrast, honesty in education predominately concerned accurate assessment, avoiding plagiarism and acts of dishonesty in a private capacity which could weaken the reputation and public trust in the teaching profession. Medicine and nursing documents typically refer to a duty of candour to those in their care, whereas honesty in the legal profession often referred to financial dealings. Thus, although a variety of virtues are stated within professional codes, an important distinction is to whom these virtues are aimed towards and what underlying purpose these virtues intend to serve. Employing stable trait-like qualities for an extrinsic, self-serving or unethical purpose may result in such qualities operating as vices rather than virtues (Kristjansson, 2015, p. 26-27).

When virtues were mentioned in these documents, they were generally directed towards three distinct stakeholders: those the profession intends to serve, the profession as a whole, and wider society at large. The degree of emphasis towards each of these varied between each profession. Within nursing and medicine, the protection of the patient from professional misconduct was most prevalent, with virtues such as integrity, trustworthiness, openness, politeness, and compassion all accentuated to treat patients with 
respect, dignity and impartiality. These qualities are particularly stressed, given the vulnerable position that patients are in when in care. This protection of the patient, which also includes their families and carers, is stated as the primary concern over the protection of colleagues and any concerns regarding work-time, under-staffing, lack of resources and dealing with risk. This is notable considering that nurses and doctors have been found to report the highest levels of work-related constraints (e.g. time pressures, work-stress, and lack of resources) compared to their education, legal and business counterparts (Arthur et al., 2019). Whilst a prioritisation of the patient is understandable given the potentially critical consequences of medical malpractice, it seems essential that nurses and doctors are also offered professional support within their working practices. This portrayal of virtues towards patients was also often associated with a sense of 'duty', with doctors and nurses 'obligated' to be an advocate for their patients. Such wording may promote more deontological (i.e. duty-based) justifications for the application of these virtues as opposed to phronesisguided moral reasoning (e.g. Kristjánsson et al., 2017b). This, coupled with work-related constraints, may lead to using the code and its rules as a means to legitimise potential actions which could cause harm to vulnerable individuals in their care.

In contrast to medicine and nursing, the education profession has illustrated a predominant focus on safeguarding the reputation of the teaching profession in the public eye, with protection of teachers' working rights and tackling issues of criticism very prevalent. This focus on protecting teachers' reputation is particularly emphasised within professional membership organisations (see Appendix Documents 2.4. and 2.6) and those directed at headteachers (see Appendix Document 2.2). Although teachers are stated to have a 'moral obligation' towards pupils to treat them with dignity, respect, and observe proper boundaries, this is often framed for the purpose of upholding the public trust and reputation for the profession (see Appendix Document 2.1). In fact, teachers' demonstration of competency and protection from criticism is portrayed as central to teachers' normal standards, and often requires teachers to balance their interest between the welfare of pupils and protection of the teaching colleagues (see Article 10 of the Appendix Document 2.4). For instance, teachers are obligated to treat all discussions about other teachers' performance with confidentiality and should not denigrate or criticise themselves in the presence of third parties (see Appendix Document 2.4). Consequently, regulatory documents within education read as placing the assessment of teaching standards and meeting external expectations at the forefront of teaching practice, as opposed to being driven by the ethical implications for those it serves. In fact, the upholding of professional reputation also seems to be a visible objective for 
each of the other professions. All professions appear to have an underlying concern with ensuring the reputation and trust bestowed by the public are not diminished or brought into disrepute (e.g. see Appendix Documents 4.9 and Article 20 of Appendix Documents 1.1). Consequently, many documents issued by professional membership organisations, particularly in education, portray the protection of the profession as of paramount importance - sometimes over the development of ethical service for others.

Professional documents from business and law demonstrate a strong focus on promoting public and client interest. For example, clients' interests are often placed before the own interests of the practitioners or the organisation, and if clients' interests and public interest collide, then the public interest should take precedence (e.g. see Article 2.2 of the Appendix Document 3.7 and Appendix Document 4.2). Practitioners from these two professions are expected to practise with virtues such as honesty, integrity and justice, however exercising independent judgement is given particular emphasis, more so than in medicine or education. Although virtues are required to be directed in the best interest of the clients, this 'interest' can appear ambiguous and based on professionals' subjective interpretation. Practitioners from business and law have been found to give higher importance to intellectual virtues, as opposed to nurses that typically gave higher worth to moral virtues (see Arthur et al., 2014; Kristjánsson et al., 2017a; 2017b). The public eye might sometimes deem a relationship with the client that is required and protected by the duty of confidentiality to be unethical. The most debatable standards of moral behavior seem to be reflected from documents within the legal profession. Although lawyers are required not to behave in a way which may diminish public trust and confidence, the Appendix Document 3.1 also clearly states that barristers will not be deemed to have acted against the precepts of the code even if they commit a minor criminal offence or their unethical conduct relates to private or personal matter. This observation is interesting in light of practitioners from the legal profession reporting the lowest levels of professional purpose towards a greater public good than those working in medicine, education and business (Arthur et al., 2019).

Another notable distinction is that doctors, nurses and teachers are expected to act as role models for those they serve and work alongside. For instance, it is expressed that doctors should be role models for both their colleagues and the wider public outside of their team. Similarly, nurses are required to be exemplars for their patients, trainee nurses and the general public. Teachers are obliged to consistently demonstrate the positive attitudes, values and behaviour which are expected of pupils (see Appendix Documents 2.1). Role models in education have traditionally related to maintaining high academic standards. However, recent 
movements in government policy suggest that greater importance may be placed on teachers characterising exemplars of 'good' character for pupils and the education profession (Hinds, 2019). Exemplifying a role model figure is particularly highlighted for head-teachers as they should set an example for others (i.e. pupils, teachers and those beyond the school bounds) and act as 'guardians of the nation's schools' (see Appendix Documents 2.2, p. 5). Within the business and legal professions, however, reference to being role models for others and the general public is absent. Although legal and business practitioners are emphasised to work for the betterment of their clients and general public, in general it seems there are no specified expectations for them to act as moral exemplars for these people.

\section{PROFESSIONAL JUDGEMENT}

According to Aristotle's notion of 'good' character, a professional requires a sense of practical wisdom (phronesis), or good judgement, to know when to apply a particular virtue after a process of reflection and deliberation (Aristotle, 2009 [1140a24-30, 1140b623]). Documents from all professions stipulate that practitioners require good judgement and are accountable for their own actions. For example, nurses are required to demonstrate a cultural awareness to help prioritise the individual patients' needs, lawyers are required to determine the specific needs of their clients in accord with the precepts of justice, and teachers are obligated to adjust their teaching methods for the diverse needs of students. Yet, many documents seem to bind their members to strictly adhere to specified rules and procedures, without offering guidance on how to approach ethical dilemmas they encounter in their practice. According to Appendix Document 1.1, nursing professionals are required to keep to the relevant laws and policies about caring for vulnerable people and those about mental capacity, ensuring the rights and best interests of those who lack capacity are still at the centre of the decision-making process (see Article 4.3 and Article 17.3 of Appendix Document 1.1). Such wording seems to overlook, and possibly impede, the potential that nursing situations may require moral judgement when the laws or rules might undermine best interests of those who lack capacity.

Equally, the use of professional judgement in education is portrayed somewhat vaguely. In fact, it was expressed that reasonable teaching conduct and practice can be determined if "no reasonable member of the profession' would have acted in an alternative way (see Appendix Document 2.6). This classification does not encourage volitional and independent reflection in teaching situations, and may lead teachers to follow formulaic standards or previous teaching action without deliberation of the ethical circumstances. Consequently, it would seem difficult for teachers to fulfil their aforementioned duty to be a role model for others when restricted in 
applying a degree of their own judgement. Teachers are also required to demonstrate a commitment to evaluate and challenge not only their practice, but also their values and beliefs (see Appendix Document 2.7. point 2 and Appendix Document 2.6, p. 4). This requirement does not refer to an improper expression of those values or opinions, but applies to an internal system of beliefs, which seems difficult or impossible for professional organisations to enforce. Such statements raise questions if teachers' freedom of holding beliefs and values might be compromised at times. Although members of professions need to share common ethical standards of conduct, practitioners also have a right to have their autonomy respected by the regulators and associations. Professions need to provide room for diversity among their members in terms of holding and expressing personal views (e.g. political, religious, social).

Alternatively, documents in business and law appear to offer members more scope in applying their own judgement and, at times, openly encourage this. For instance, lawyers are obligated to use their own professional judgment regarding matters on which they are instructed, independent of the views of clients or employers, and must be able to justify their decisions and actions (see Appendix Document 3.1). Likewise, business professionals are required to judge how their work is "not only within the law but also within the spirit of the law' (see Article 1.6. of Appendix Document 4.8). Considering neither business nor legal professionals have any salient duty to act as role models, there may be a concern that when professional judgement is not used for aspirational reasons, it could be exercised for self-serving purposes.

\section{APPLICATION TO PRACTICE}

A useful professional code of ethical conduct should be instructive and equipped with interpretative features that inform professionals, and the constituencies to which professionals are held responsible, how to apply general rules to specific situations using autonomous judgements (Jamal and Bowie, 1995). The analysis indicated that interpretative features were often scarce within the documents, with more detailed guidance sometimes offered in separate policy papers and statements (e.g. see Appendix Document 1.3). One potentially useful example in helping develop practitioners' moral reasoning was evident in the business profession (see Appendix Document 4.8). This document encourages members to ask themselves questions such as 'do I think it is OK if I don't get caught?', and deliberate if they should say 'show me where it says I can't' or 'is this ethical?' (see Article 1.6. of the Appendix Document 4.8). Pondering on such questions may help business professions develop habits of moral judgement when deliberating what action to take in professional scenarios. 
The most detailed and clearest guidance for practitioners across the documents is often provided in regards to avoiding or dealing with occasions of unethical behaviours, as opposed to how to enhance or facilitate ethical practice. For example, there are very detailed and clear processes outlined for doctors and nurses in how to apologise to patients according to the NHS Litigation Authority (see Appendix Document 1.9, p. 3). Ethical practice is also seen to be protected across all professions by the comprehensive promotion of whistleblowing. So much so, that there is a trend to protect those members who report occasions of malpractice, and to sometimes even punish those that do not raise concerns. All professions promote whistleblowing, although they use different terms to denote this action (e.g. raising concerns in medicine; public interest disclosure in law). Indeed, a four stage process is stated within nursing detailing how practitioners should blow the whistle (see Appendix Document 1.3).

Whistleblowing is used as a deterrent for practitioners practicing unethically or corruptly. Indeed, sanctions were evident in the majority of reviewed documents. Across all professions, a failure to comply with ethical standards may cause a professional to be subject to disciplinary action, and in serious cases even result in removal from their practice. Violating core standards set by professional membership bodies can result in having the membership suspended or cancelled. Doctors and lawyers have special tribunals that examine the cases of misconduct. Disciplinary tribunals are independent from the regulators, which makes the system fairer compared to the system where the regulator is not only deciding about the content of the code, but also executing the consequences of the failure to follow the code. Punishment is often seen as a mechanism to control undesirable behaviour. Yet practitioners may obey rules because of pressure, introjection and the fear of sanctions, which may actually impede autonomous moral growth (see Ryan, Curren \& Deci, 2013).

The emphasis of sanctions for professional misconduct raises questions about the purpose of the codes of ethical conduct. Are they aimed to morally develop the members of the professions or are they quasi-legal documents which focus on informing practitioners about sanctions for unethical behaviours without necessarily imposing a moral judgement towards their behaviours? While rules and regulations are important to guide normative practices, an emphasis of adherence to these rules and avoidance of potential sanctions may lead to issues with poor decision-making. For example, practitioners may attempt to find 'loop holes' in the rules to still operate within the letter, rather spirit, of the profession (Furlong et al., 2017, p. 213). 


\section{CONCLUDING THOUGHTS}

Ethical behaviour from a normative perspective is usually understood as following rules, decisions based on any potential consequences and fostering internal moral qualities for human flourishing (see Anscombe, 1958; MacIntyre, 1981). Although the process of codifying professional conduct is in itself deontological (rule-focused), a code of ethical conduct should still depict a balanced orientation towards compliance with rules, consequences or ethical development. The analysis of the examined documents, however, indicates that professional codes seem to emphasise conformity among its own members to the rules of the codes rather than developing their autonomous interest in ethical professional practice.

Codes of conduct should have a slightly different purpose than just enforcing the most basic competences and standards. Professional codes should ideally be reflective of character and virtues rather than existing as a set of ethical rules specific to a profession (Carr, 2018; Furlong et al., 2017). Ethical practice may ensue when members display a higher level of ethical discernment underpinned by virtues such as humanity, kindness, compassion, justice and integrity. This is only possible when professionals are able to make decisions based on conscience and the autonomy and diversity among practitioners is respected. Rule-based thinking may need to be adapted to focus on developing practitioners' character-informed judgements, as it is not enough that virtues are practiced in a robotic manner to fulfil the rules or standards included in the code. While conformity to standards of practice may prevent professionals from exploiting vulnerable members of public, the promotion of ethical professional conduct may be better served by shifting the main focus of professional documents from protecting the reputation of the profession towards promoting ethical practice for the benefit of individuals and the public which, in turn, should safeguard and enhance the reputation of the professions in the public eye. Alongside these codes, professional regulators and membership organisations could develop ethical training programmes to help promote ethical awareness and guide processes of judgement and deliberation in practitioners' everyday practice. 


\section{Bibliography}

Anscombe, G.E.M. (1958) Modern moral philosophy. Philosophy, 33(124), pp.1-19.

Aristotle (2009) The Nicomachean Ethics (Oxford World's Classics), Oxford: Oxford University Press

Arthur, J., Earl, S., Thompson, A., and Ward, J. (2019) Repurposing the Professions: The Role of Professional Character. Initial Insights Research Report, Birmingham: Jubilee Centre for Character and Virtues, University of Birmingham.

Arthur, J., Fullard, M., Watts, P., and Moller, F. (2019) Character Perspectives of Student Teachers. Initial Insights Research Report, Birmingham: Jubilee Centre for Character and Virtues, University of Birmingham.

Arthur, J., Kristjánsson, K., Thomas, H., Holdsworth, M., Badini Confolonieri, L., and Qiu, T. (2014) Virtuous Character for the Practice of Law: Research Report, Birmingham: Jubilee Centre for Character and Virtues, University of Birmingham.

Arthur, J., Kristjánsson, K., Thomas, H., Kotzee, B., Ignatowicz, A., and Qiu, T. (2015a) Virtuous Medical Practice: Research Report, Birmingham: Jubilee Centre for Character and Virtues, University of Birmingham.

Arthur, J., Kristjánsson, K., Cooke, S., Brown, E. and Carr, D. (2015b) The Good Teacher: Understanding Virtues in Practice: Research Report, Birmingham: Jubilee Centre for Character and Virtues, University of Birmingham.

Arthur, J., Walker, D,I., and Thoma, S. (2018) Soldiers of Character: Research Report, Birmingham: Jubilee Centre for Character and Virtues, University of Birmingham.

Carr, D. (2018) 'Introduction', in Cultivating Moral Character and Virtue in Professional Practice, Carr, D. (Ed.) Abingdon: Routledge, pp. 1-12

Carr, D, Bondi, L, Clark, C. and Clegg, C. (2011) 'Introduction: Towards Professional Wisdom', in Carr, D, Bondi, L, Clark, C. and Clegg, C. (Eds.) Towards Professional Wisdom: Practical Deliberation in the People Professions, Surrey: Ashgate, pp. 1-10

Furlong, W., Crossan, M., Gandz, J. and Crossan, L. (2017) Character's Essential Role in Addressing Misconduct in Financial Institutions. Bus. L. Int'l, 18, p.199.

Harzer, C. and Ruch, W. (2013) The application of signature character strengths and positive experiences at work. Journal of Happiness Studies, 14(3), pp.965-983.

Harzer, C. and Ruch, W. (2014) The role of character strengths for task performance, job dedication, interpersonal facilitation, and organizational support. Human Performance, 27(3), pp.183-205.

Harzer, C. and Ruch, W. (2015) The relationships of character strengths with coping, workrelated stress, and job satisfaction. Frontiers in psychology, 6 (165), pp. 1-12 
Hinds, D. (2019) Education Secretary sets out vision for character and resilience. Department of Education. Available at:

https://www.gov.uk/government/news/education-secretary-sets-out-vision-forcharacter-and-resilience. [Accessed 14 ${ }^{\text {th }}$ March, 2019].

Jamal, K. and Bowie, N.E. (1995) Theoretical considerations for a meaningful code of professional ethics. Journal of business ethics, 14(9), pp.703-714.

Jubilee Centre for Character and Virtues (2016) Statement on Character, Virtue and Practical Wisdom in Professional Practice, Birmingham: Jubilee Centre for Character and Virtues, University of Birmingham.

Jubilee Centre for Character and Virtues (2017) A Framework for Character Education in Schools, Birmingham: University of Birmingham, Jubilee Centre for Character and Virtues.

Kristjánsson, K. (2015), Aristotelian Character Education, Abingdon: Routledge.

Kristjánsson, K., Arthur, J., Moller, F. and Huo, Y. (2017a) Character Virtues in Business and Finance: Research Report, Birmingham: Jubilee Centre for Character and Virtues, University of Birmingham.

Kristjánsson, K., Varghese, J., Arthur, J. and Moller, F. (2017b) Virtuous Practice in Nursing: Research Report, Birmingham: Jubilee Centre for Character and Virtues, University of Birmingham.

MacIntyre, A. (1981) After Virtue: A Study in Moral Theory, London: Duckworth

Moore, G. (2015) Corporate character, corporate virtues, Business Ethics: A European Review, vol. 24, no.2, pp. 99-114.

Moore, G. (2017) Virtue at work: Ethics for individuals, managers, and organizations, Oxford University Press.

Peterson, C., Stephens, J.P., Park, N., Lee, F. and Seligman, M.E. (2010) 'Strengths of Character and Work', pp.221-231. In Linley, P.A., Harrington, S. \& Page, N (Eds.). Handbook of Positive Psychology and Work, Oxford: Oxford University Press.

Ryan, R. M., Curren, R. R., and Deci, E. L. (2013). 'What humans need: Flourishing in Aristotelian philosophy and self-determination theory', In A. S. Waterman (Ed.) The best within us: Positive psychology perspectives on eudaimonia, pp. 57-75, Washington, DC, US: American Psychological Association.

Sama, L.M. and Shoaf, V. (2008) Ethical leadership for the professions: Fostering a moral community, Journal of Business Ethics, 78(1-2), pp.39-46. 
Dr Stephen Earl

School of Education

Jubilee Centre for Character and Virtues

School of Education

University of Birmingham
Dr Maria Moulin-Stozek

School of Education

Jubilee Centre for Character and Virtues

School of Education

University of Birmingham

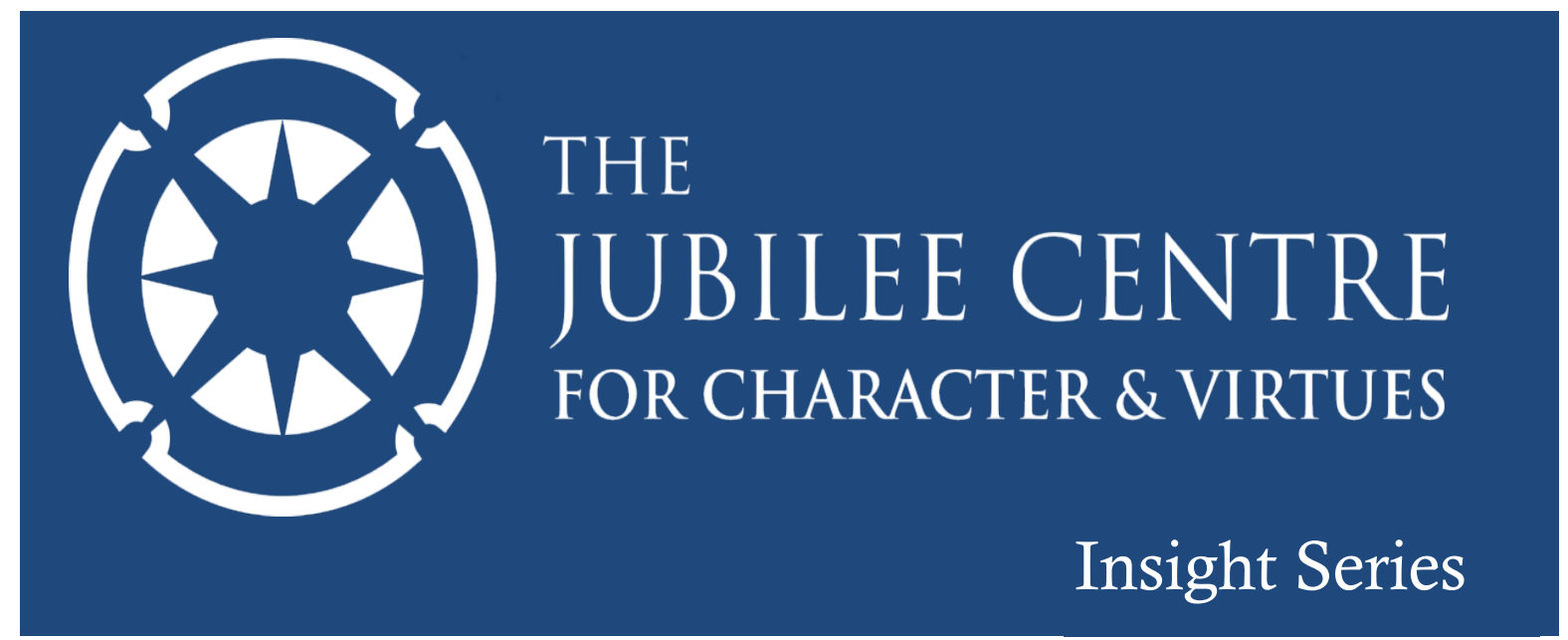

\section{The Jubilee Centre for Character and Virtues}

- Pioneering interdisciplinary research of international standing focussing on character, virtues and values in the interest of human flourishing.

- Promoting a moral concept of character in order to explore the importance of virtue for public and professional life.

- A leading informant on policy and practice in this area through an extensive range of research and development projects contributing to a renewal of character and values in both individuals and societies.

The views expressed in this article are those of the authors and do not necessarily reflect the official policy or position of The Jubilee Centre for Character and Virtues or The University of Birmingham. 